УДК 624.012.45

DOI https://doi.org/10.32782/2664-0406.2020.38.3

\title{
Азизов Т.Н.
}

д.т.н., профессор,

Уманский государственный педагогический университет имени Павла Тычины, г. Умань, Черкасская область

\section{Орлова О.М.}

преподаватель,

Уманский государственный педагогический университет имени Павла Тычины, г. Умань, Черкасская область

\section{ОПРЕДЕЛЕНИЕ ПЕРЕМЕЩЕНИЙ ПРИ КРУЧЕНИИ ДВУТАВРОВОГО ЭЛЕМЕНТА С НОРМАЛЬНЫМИ ТРЕЩИНАМИ ИНЖЕНЕРНЫМ МЕТОДОМ}

Анотащія. Завдання визначення жорсткості елемента двотаврового перерізу складається з трьох етапів розрахунку. Спочатку умовно розтинається поздовжня арматура в місиі, де розташована нормальна трішина, $і$ визначається взаємне зміщення берегів тріщини. На другому етапі визначається нагельна сила в поздовжній арматурі. Знаючи величину нагельної сили, неважко визначити крутильну жорсткість елемента (третій етап завдання). Перший етап завдання є основним і найбільш складним. Стаття присвячена вирішенню складної частини завдання - визначенню взаємного переміщення берегів нормальної трішини елемента двотаврового перерізу з розсіченою арматурою.

Згідно із запропонованою методикою реальний елемент з нормальною тріщиною замінений елементом з різними твердостями по ділянках. Розглянуто загальний випадок, коли висоти нормальних тріщинув межах одного блоку різні. При цьому висота зони без тріщин може перебувати як у межах ребра двотаврової балки, так $і$ в ї полииях.

На діляниі за нормальної тріщиною прийнята гіпотеза, що висота перерізу елемента змінюється від висоти, що дорівнює висоті зони над тріщиною, до повної висоти перерізу. Причому зміна висоти відбувається за законом прямої лінї. Ця лінія нахилена під деяким кутом до горизонталі. Показано, що якщо прийняти кут нахилу цієї лінї рівним 45 градусів, то результати виходять досить точними. Еквівалентна висота перерізу визначена як середне значення між висотою над тріщиною і повною висотою перерізу. Еквівалентна крутильна жорсткість елемента на ділянці похилої лінї приймається рівною жорсткості елемента з умовно постійною жорсткістю при постійній висоті, рівній еквівалентної. Наведено порівняння розрахунків за запропонованою методикою з даними розрахунку в програмі Ліра із застосуванням об'ємних кінцевих елементів. Порівняння показало хороший збіг даних. Середнє значення похибки склало 6,9 відсотка, а коефічієнт варіацї 0,45\%.

Запропонована методика розрахунку дозволяє визначити переміщення в нормальній тріщині без використання програмних комплексів із застосуванням об'ємних кінщевих елементів. Будучи абсолютно простою, методика має достатню для інженерних розрахунків точність.

Ключові слова: двотавровий елемент, нормальна тріщина, крутильна жорсткість, момент інерцї при крученні, еквівалентна жорсткість. 
Постановка проблемы. Определению напряженно-деформированного состояния двутавровых балок при изгибе уделено достаточно много внимания. В то же время исследованию НДС таких балок при действии крутящих моментов посвящено ограниченное количество работ [3]. Прочности и деформативности железобетонных балок при кручении посвящено достаточно много работ [6; 7]. Однако в этих работах рассматриваются только элементы со спиральными трещинами. Однако особенные проблемы встречаются при расчете перемещений при кручении двутавровых балок с нормальными трещинами. Существующие методы расчета на кручение предполагают равномерное распределение крутящего момента по всему сечению [4]. А в случае нормальной трещины крутящий момент передается только через часть сечения. Использование метода конечных элементов в таких случаях не всегда является приемлемым и удобным [1].

Анализ исследований. Известно [1; 5], что пространственная работа накладывает существенный отпечаток на напряженно-деформированное состояние плоских перекрытий, мостов, балочных клеток и других плитно-ребристых систем. Кроме того, при опирании перекрытия не только торцами, но и продольными сторонами эффект пространственной работы проявляется даже если все перекрытие загружено равномерно распределенной нагрузкой. Известно также
[1; 2; 5], что на пространственную работу ребристой системы существенное влияние оказывают изгибные и крутильные жесткости отдельных балок. В ребристых системах главные балки могут иметь тавровое, двутавровое, коробчатое сечение.

В работе [3] представлена методика аналитического расчета перемещений при кручении железобетонных двутавровых балок с нормальными трещинами. Однако эта методика дает погрешность при больших толщинах полок и стенки двутаврового элемента. Учитывая, что железобетонные двутавровые балки достаточно часто имеют болышие толщины полок и ребра, необходима разработка инженерных методик расчета, позволяющих перемещения в нормальной трещине при кручении не зависимо от толщин элементов балки.

В связи с вышесказанным целью настоящей статьи является разработка инженерного метода расчета перемещений при кручении железобетонного двутаврового элемента с нормальной трещиной.

Результаты исследований. Известно [2; 9], что для расчета перемещений в нормальной трещине следует сначала рассмотреть перемещение в трещине с условно рассеченной арматурой. Эта задача является наиболее сложной в общей задаче определения жесткости железобетонного элемента с нормальной трещиной.

На рис. 1 представлена схема такого элемента с уже рассеченной арматурой. Основной задачей при этом является

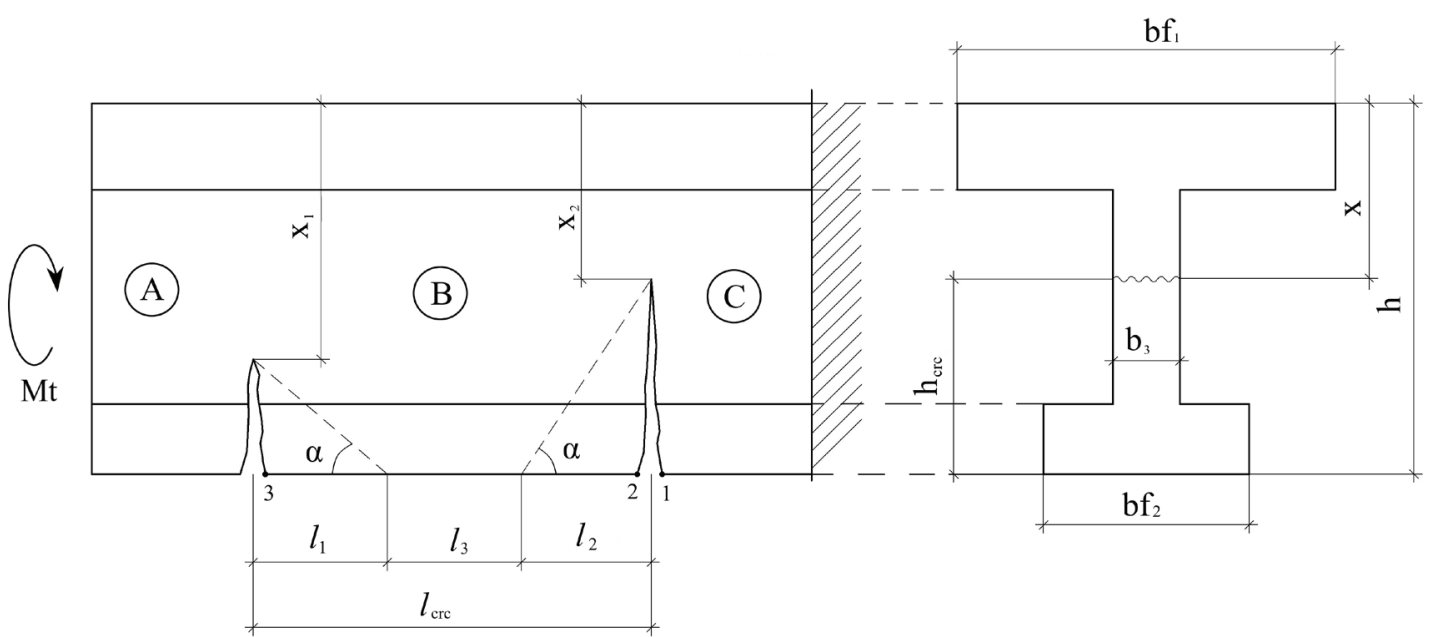

Рис. 1. Схема кручения двутаврового элемента с нормальными трещинами 
определение взаимного смещения точек 1 и 2 в трещине при действии крутящего момента $\boldsymbol{M}_{\boldsymbol{t}}$.

В общем случае высота зоны над нормальной трещиной $\boldsymbol{x}_{1}$ с левой стороны блока В и высота $\boldsymbol{x}_{2}$ с правой стороны этого блока не равны. При этом высота зоны без трещин может находиться как в пределах ребра двутавровой балки, так и в ее полках.

Крутящий момент от блока А к блоку В передается через часть сечения. В месте наличия трещины жесткость сечения (как изгибная, так и крутильная) резко изменяется. В работе [2] было показано, что в таком случае элемент можно рассчитывать как условный элемент с сечением, высота которого изменяется по некоторой кривой. Представим, что в нашем случае высота элемента изменяется по закону прямой линии как это сделано в [8] для расчета железобетонных балок при изгибе. При этом она изменяется от малой величины $\boldsymbol{x}_{1}$ (для блока В на рис. 1 слева направо) до полной высоты $\boldsymbol{h}$. Аналогично с правой стороны блока В линия изменения расчетной высоты сечения будет изменяться от $\boldsymbol{x} \mathbf{2}$ до $\boldsymbol{h}$. Обозначим через $\boldsymbol{\alpha}$ угол наклона этих линий к горизонтали.

На длине $\boldsymbol{l}_{3}=\boldsymbol{l}_{\boldsymbol{c} \boldsymbol{c}}-\boldsymbol{l}_{\mathbf{1}}-\boldsymbol{l}_{2}$ элемент имеет полную высоту сечения, a, следовательно, и полную жесткость. Длину блока В между нормальными трещинами обозначим через $\boldsymbol{l}_{\boldsymbol{c} \boldsymbol{c}}$, что является расстоянием между наклонными трещинами, которое может быть определено любым из известных методов [8], в том числе по нормативным документам.

В сечении с трещиной слева от блока В момент инерции при кручении $\boldsymbol{J}_{\boldsymbol{c} \boldsymbol{c}, \boldsymbol{1}}$ будет равен моменту инерции таврового элемента высотой $\boldsymbol{x}_{1}$ и полкой в верхней зоне; в сечении справа от этого блока момент инерции при кручении $\boldsymbol{J}_{\boldsymbol{c} r, 2}$ будет равен моменту инерции тавра с высотой сечения $\boldsymbol{x}_{2}$.

Учитывая принятое предположение о линейном изменении высоты, мы можем представить двутавровую балку в виде элемента со ступенчато изменяемой высотой (рис. 2).

При этом высота сечения на длине $\boldsymbol{l}_{\boldsymbol{1}}$ и на длине $\boldsymbol{l}_{\boldsymbol{2}}$ соответственно будет определяться по естественным формулам из геометрических построений:

$$
h_{e k v, 1}=\frac{x_{1}+h}{2} ; h_{e k v, 2}=\frac{x_{2}+h}{2}
$$

Крутильные жесткости элементов на участках длиной $\boldsymbol{l}_{\boldsymbol{1}}$ и $\boldsymbol{l}_{\boldsymbol{2}}$ будут определяться как для тавровых элементов с соответствующей высотой сечения $\boldsymbol{h}_{\boldsymbol{e} \boldsymbol{k}, \boldsymbol{1}}$ и $\boldsymbol{h}_{\boldsymbol{e} \boldsymbol{k}, \boldsymbol{2}}$,

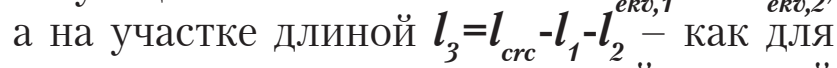
двутаврового элемента с полной высотой сечения $\boldsymbol{h}$.

Длины $\boldsymbol{l}_{1}$ и $\boldsymbol{l}_{2}$ легко определяются из геометрических построений при известном угле наклона $\boldsymbol{\alpha}$ (см. рис. 1). Зная высоты $\boldsymbol{h}_{\boldsymbol{e k v , 1}}$ и $\boldsymbol{h}_{\boldsymbol{e} v, 2}$, а также длины $\boldsymbol{l}_{\boldsymbol{1}}$ и $\boldsymbol{l}_{2}$, не труд-

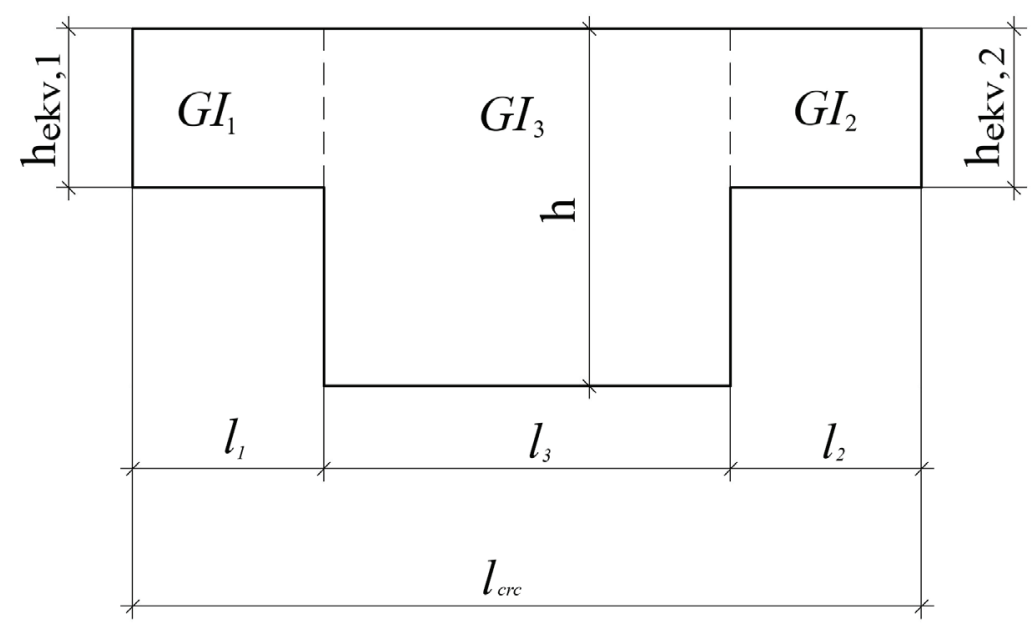

Рис. 2. Схема представления элемента со ступенчатым изменением высоты 
но вычислить все моменты инерции при кручении $\boldsymbol{J}_{\boldsymbol{1}}, \boldsymbol{J}_{2}$ и $\boldsymbol{J}_{3}$, а, следовательно, и жесткости на этих соответствующих участках $\boldsymbol{G J}_{\mathbf{1}}, \boldsymbol{G} \boldsymbol{J}_{2}$ и $\boldsymbol{G J}_{3}$.

Для решения основной задачи определения крутильной жесткости элемента с нормальными трещинами нужно знать взаимное смещение точек 1 и 2 на рис. 1.

Для этого следует от угла поворота между точками 1 и 3 отнять угол поворота между точками 2 и 3, т.е.:

$$
\phi_{1-2}=\phi_{1-3}-\phi_{2-3}
$$

Угол поворота между точками 2 и 3 определяется известными методами сопро- тивления материалов [10] для двутаврового элемента с полной высотой сечения h:

$$
\phi_{2-3}=\frac{M_{t} l_{3}}{G J_{3}}
$$

А угол поворота между точками 1 и 3 (см. рис. 1) с учетом представления элемента с трещинами по рис. 1 как элемент со ступенчатым изменением высоты сечения по рис.2 будет определен из выражения:

$$
\phi_{1-3}=\frac{M_{t}}{G}\left(\frac{l_{1}}{J_{1}}+\frac{l_{2}}{J_{2}}+\frac{l_{3}}{J_{3}}\right) .
$$

\begin{tabular}{|c|c|c|c|c|c|c|c|c|c|c|c|}
\hline $\begin{array}{c}\text { № } \\
\text { П/ா }\end{array}$ & $\begin{array}{l}\mathrm{bf}_{1} \\
(\mathrm{M})\end{array}$ & $\begin{array}{l}\mathrm{hf}_{1} \\
(\mathrm{M})\end{array}$ & $\begin{array}{l}\mathrm{bf}_{2} \\
(\mathrm{M})\end{array}$ & $\begin{array}{l}\mathrm{hf}_{2} \\
\text { (M) }\end{array}$ & $\begin{array}{c}\mathrm{t} \\
(\mathrm{M})\end{array}$ & $\begin{array}{l}\mathrm{h}_{3} \\
(\mathrm{M})\end{array}$ & $\begin{array}{l}h_{\text {crc }} \\
\text { (M) }\end{array}$ & $\begin{array}{l}1_{\text {cre }} \\
(\mathrm{M})\end{array}$ & $\begin{array}{l}\Delta_{\text {teor }} \\
(\mathrm{MM})\end{array}$ & $\begin{array}{l}\Delta_{\text {Lira }} \\
(\mathrm{MM})\end{array}$ & $\begin{array}{c}\text { Погреш- } \\
\text { ность } \delta \%\end{array}$ \\
\hline 1 & 0.30 & 0.03 & 0.09 & 0.05 & 0.03 & 0.15 & 0.110 & 0.30 & 80.65 & 87.81 & 8.15 \\
\hline 2 & 0.30 & 0.03 & 0.09 & 0.05 & 0.03 & 0.15 & 0.123 & 0.30 & 84.37 & 91.80 & 8.09 \\
\hline 3 & 0.30 & 0.03 & 0.09 & 0.05 & 0.03 & 0.15 & 0.174 & 0.30 & 102.37 & 106.64 & 4.00 \\
\hline 4 & 0.30 & 0.03 & 0.09 & 0.05 & 0.03 & 0.15 & 0.142 & 0.30 & 90.48 & 97.69 & 7.38 \\
\hline 5 & 0.30 & 0.03 & 0.09 & 0.05 & 0.03 & 0.15 & 0.045 & 0.30 & 65.72 & 70.00 & 6.11 \\
\hline 6 & 0.30 & 0.03 & 0.09 & 0.05 & 0.03 & 0.15 & 0.058 & 0.30 & 68.22 & 74.73 & 8.72 \\
\hline 7 & 0.20 & 0.03 & 0.09 & 0.05 & 0.03 & 0.15 & 0.110 & 0.30 & 105.88 & 111.22 & 4.80 \\
\hline 8 & 0.20 & 0.03 & 0.09 & 0.05 & 0.03 & 0.15 & 0.123 & 0.30 & 112.09 & 117.69 & 4.76 \\
\hline 9 & 0.20 & 0.03 & 0.09 & 0.05 & 0.03 & 0.15 & 0.174 & 0.30 & 143.00 & 143.56 & 0.39 \\
\hline 10 & 0.20 & 0.03 & 0.09 & 0.05 & 0.03 & 0.15 & 0.142 & 0.30 & 122.42 & 127.58 & 4.04 \\
\hline 11 & 0.20 & 0.03 & 0.09 & 0.05 & 0.03 & 0.15 & 0.045 & 0.30 & 81.56 & 83.78 & 2.66 \\
\hline 12 & 0.20 & 0.03 & 0.09 & 0.05 & 0.03 & 0.15 & 0.058 & 0.30 & 85.55 & 90.55 & 5.52 \\
\hline 13 & 0.30 & 0.04 & 0.09 & 0.05 & 0.03 & 0.14 & 0.110 & 0.30 & 43.92 & 49.02 & 10.41 \\
\hline 14 & 0.30 & 0.04 & 0.09 & 0.05 & 0.03 & 0.14 & 0.123 & 0.30 & 45.08 & 50.28 & 10.35 \\
\hline 15 & 0.30 & 0.04 & 0.09 & 0.05 & 0.03 & 0.14 & 0.174 & 0.30 & 50.48 & 54.21 & 6.88 \\
\hline 16 & 0.30 & 0.04 & 0.09 & 0.05 & 0.03 & 0.14 & 0.142 & 0.30 & 46.99 & 52.01 & 9.66 \\
\hline 17 & 0.30 & 0.04 & 0.09 & 0.05 & 0.03 & 0.14 & 0.045 & 0.30 & 39.12 & 43.53 & 10.14 \\
\hline 18 & 0.30 & 0.04 & 0.09 & 0.05 & 0.03 & 0.14 & 0.058 & 0.30 & 39.95 & 45.31 & 11.84 \\
\hline \multicolumn{11}{|c|}{ Среднее значение \% } & 6.9 \\
\hline \multicolumn{11}{|c|}{ коэффициент вариации \% } & 0.45 \\
\hline
\end{tabular}

Таблица 1. Сравнение перемещений, определенных по разработанной методике и по программе Лира с применением объемных конечных элементов 
где $\boldsymbol{J}_{1}$ и $\boldsymbol{J}_{2}$, как было сказано выше, это моменты инерции при кручении тавров с высотой соответственно $\boldsymbol{h}_{\boldsymbol{e} \boldsymbol{k}, 1}$ и $\boldsymbol{h}_{\boldsymbol{e k v , 2},}$, а $J_{3}-$ момент инерции двутаврового (полного) сечения с полной высотой $\mathbf{h}$ (см. рис. 2).

Если расстояние между трещинами $\boldsymbol{l}_{\boldsymbol{c r c}}$ таково, что $\boldsymbol{l}_{3}=\boldsymbol{l}_{\boldsymbol{c} \boldsymbol{c}}-\boldsymbol{l}_{\mathbf{1}}-\boldsymbol{l}_{2} \leq \boldsymbol{0}$, то в формуле (4) член, содержащий момент инерции $J_{3}$ будет отсутствовать, а моменты инерции $\boldsymbol{J}_{1}$ и $\boldsymbol{J}_{3}$ будут равны моментам инерции элемента с высотами соответственно:

$$
h_{e k v, 1}=\frac{x_{1}+h_{s r}}{2} ; h_{e k v, 2}=\frac{x_{2}+h_{s r}}{2}
$$

где через $\boldsymbol{h}_{\boldsymbol{s}}$ обозначена высота от верхней грани элемента до точки пересечения наклонных прямых слева и справа (см. рис. 1).

Следует отметить, что если величина эквивалентной высоты $\boldsymbol{h}_{\boldsymbol{e}}$ ил, дет такой, что $\boldsymbol{h}_{\boldsymbol{e} \boldsymbol{v}}>\boldsymbol{h}$ - $\boldsymbol{h}_{f 1}\left(\right.$ где $\boldsymbol{h}_{\boldsymbol{f} 1}-$ ТоЛщина верхней полки двутавра), то момент инерции $\boldsymbol{J}_{1}$ (или $\boldsymbol{J}_{2}$ ) будет уже определяться как для двутаврового сечения с нижней полкой, толщина которой равна $\boldsymbol{h}-\boldsymbol{h}_{\boldsymbol{e k v}}$.

Для проверки достоверности и точности методики расчета было проведено сравнение расчетов по приведенной методике с расчетами в программе Лира с использованием объемных конечных элементов. Ниже в таблице 1 приведены данные такого сравнения. Рассматривалась двутавровая балка с полной высотой сечения $\mathrm{h}=220$ мм. Варьировались ширина $\boldsymbol{b} \boldsymbol{f}_{1}$ верхней полки и ее толщина $\boldsymbol{h} \boldsymbol{f}_{\boldsymbol{1}}$; ширина и толщина нижней полки $\boldsymbol{b} \boldsymbol{f}_{2}$ и $\boldsymbol{h} \boldsymbol{f}_{2}$; высота $\boldsymbol{h}_{3}$ и толщина $\boldsymbol{t}$ стенки. Кроме того варьировалась высота трещины $\boldsymbol{h}_{\boldsymbol{c r c}}$ и рас- стояние между трещинами $\boldsymbol{l}_{c r c}$. УГол $\boldsymbol{\alpha}$ в расчетной схеме по рис. 1 был принят равным $45^{\circ}$. В таблице приведены перемещения от взаимного поворота между точками 1 и 3 (см. рис. 1), вычисленные по предложенной методике и в программе Лира.

Данные таблицы свидетельствуют о достаточной точности предложенного инженерного метода. Следует отметить, что при проведении расчетов по предложенной методике крутильные жесткости тавровых элементов определялись как сумма жесткостей прямоугольников, составляющих тавр. Если жесткость тавров определять по точной методике [4], то совпадение результатов с данными расчетом по программе Лира будет еще большим.

Выводы и перспективы исследований. Перемещение в нормальной трещине при кручении железобетонного двутаврового элемента определяется представлением такого элемента в виде элемента со ступенчатым изменением высоты сечения. Показано, что если принять угол наклона изменения высоты сечения от нормальной трещины равным $45^{\circ}$ результаты расчетов по предложенной методике имеют хорошее совпадение с расчетами по программе Лира с применением объемных конечных элементов. При этом предложенная методика обладает простотой и может быть применена в практике проектирования при расчете деформаций при кручении железобетонного двутаврового элемента с нормальными трещинами.

В перспективе предполагается распространение методики на расчет с учетом нелинейных свойств материалов.

\section{Jumepamypa}

1. Азізов Т.Н. Просторова робота залізобетонних перекриттів. Теорія та методи розрахунку: автореф. дисс. ... докт. техн. наук : 05.23.01 ; Полтавський національный технічний університет. Полтава, 2006. $35 \mathrm{c}$.

2. Азизов Т.Н.,МельникА.В,ПарамоновД.Ю.НДСипрочностьжелезобетонныхбалокснормальными трещинами при кручении. Зб. наук. пращь. Серія «Галузеве машинобудування, будівнищтво», вип. 3(25). Том 3. Полтава : ПолтНТУ, 2009. С. 9-13.

3. Азізов Т.Н., Орлова О.М. Визначення взаємного переміщення берегів нормальної тріщини при крученні залізобетонних елементів двотаврового перерізу. Вчені записки Таврійського національного університету імені B.I. Вернадського Серія: Технічні науки. Том 31 (70) № 22020. Частина 2. С. 189-197. 
4. Арутюнян Н.Х., Абрамян Б.Л. Кручение упругих тел. Москва : Физматгиз, 1963. 688 с.

5. Дроздов П.Ф. Конструирование и расчёт несущих систем многоэтажных зданий и их элементов. Москва : Стройиздат, 1977. 223 с.

6. Карпенко Н.И. Теория деформирования железобетона с трещинами. Москва : Стройиздат, 1976. 208 c.

7. Коуэн Г. Дж. Кручение в обычном и предварительно напряженном железобетоне. Москва : Издво литературы по строительству, 1972. 104 с.

8. Кочкарьов Д.В. Нелінійний опір залізобетонних елементів і конструкцій силовим впливам. Рівне : О. Зень, 2015. 384 с.

9. Срібняк Н.М. Крутильна жорсткість залізобетонних елементів перекриттів з нормальними тріщинами:автореф. дис..... канд. техн. наук 05.23.01; Одеська державнаакадемія будівництва таархітектури. Одеса, 2009. 23 с.

10.Феодосьев В.И. Сопротивление материалов. Москва : Наука, 1970. 544 с.

\section{References}

1. Azizov T.N. Prostorova robota zalizobetonnykh perekryttiv. Teoriia ta metody rozrakhunku: Avtoref. dyss. ... dokt. tekhn. nauk: 05.23.01 / Poltavskyi natsionalnыi tekhnichnyi universytet. - Poltava, 2006. $35 \mathrm{~s}$.

2. Azyzov T.N., Melnyk A.V, Paramonov D.Iu. NDS y prochnost zhelezobetonnыkh balok s normalnыmy treshchynamy pry kruchenyy // Zb. nauk. prats. Seriia «Haluzeve mashynobuduvannia, budivnytstvo», vyp. 3 (25) - Tom 3. Poltava: PoltNTU, 2009. - S. 9-13.

3. Azizov T.N., Orlova O.M. Vyznachennia vzaiemnoho peremishchennia berehiv normalnoi trishchyny pry kruchenni zalizobetonnykh elementiv dvotavrovoho pererizu// Vcheni zapysky Tavriiskoho natsionalnoho universytetu imeni V.I. Vernadskoho Seriia: Tekhnichni nauky Tom 31 (70) № 22020. Chastyna 2. - S. 189-197.

4. Arutiunian N.Kh., Abramian B.L. Kruchenyeupruhykh tel.. M.: Fyzmathyz, 1963. - 688 s.

5. Drozdov P.F. Konstruyrovanye y raschët nesushchykh system mnohoətazhnukh zdanyi y ykh эlementov. - M.: Stroiyzdat, 1977. - 223 s.

6. Karpenko N.Y. Teoryia deformyrovanyia zhelezobetona s treshchynamy. M.: Stroiyzdat, 1976. - 208 s.

7. Kouэn, H.Dzh. Kruchenye v obыchnom y predvarytelno napriazhennom zhelezobetone: Per. s anhl. / H.Dzh. Kouэn; - M.: Yzd-vo lyteraturb po stroytelstvu, 1972. - 104 s.

8. Kochkarov D.V. Neliniinyi opir zalizobetonnykh elementiv i konstruktsii sylovym vplyvam. - Rivne:

O. Zen, 2015. - $384 \mathrm{~s}$.

9. Sribniak, N.M. Krutylna zhorstkist zalizobetonnykh elementiv perekryttiv z normalnymy trishchynamy: avtoref. dys. ... kand. tekhn. nauk 05.23.01 / Sribniak Nataliia Mykolaivna; Odeska derzhavna akademiia budivnytstva ta arkhitektury. - O., 2009. - 23 s.

10.Feodosev V.Y. Soprotyvlenye materyalov. - M.: Nauka, 1970. - 544 s.

\section{DETERMINATION OF THE DISPLACEMENT DURING TORRATION OF I-BEAM ELEMENT WITH NORMAL CRACKS BY ENGINEERING METHOD}

Abstract. The problem of determining the torsional stiffness of I-beam element consists of three stages of calculation. First, the longitudinal reinforcement is conventionally cut at the place where the normal crack is located and the mutual displacement of the crack edges is determined. At the second stage, pin force in the longitudinal reinforcement is determined. Knowing the magnitude of the thrust force, it is easy to determine the torsional stiffness of the element (third stage of the problem). The first stage of the task is the main and the most difficult one. The article is devoted to solving this most difficult part of the problem - determining the mutual displacement of the sides of a normal crack of the I-beam element with sheared reinforcement.

According to the proposed technique, a real element with a normal crack is replaced by an element with different stiffness in sections. The general case is considered when the heights of normal cracks within one block are different. In this case, the height of the zone without 
cracks can be located both within the ribs of the I-beam and in its flanges.

In the area within a normal crack, there is a hypothesis that the height of the section of the element changes due to the height of the zone above the crack to the full height of the section. Moreover, the change in height occurs according to the law of a straight line. This line is inclined at some angle to the horizontal. It is shown that if we take the angle of inclination of this line equal to 45 degrees, then the results are quite accurate. The equivalent section height is defined as the average between the height above the crack and the total section height. The equivalent torsional stiffness of the element in the section of the inclined line is taken to be equal to the stiffness of the element with a conditionally constant stiffness at a constant height equal to the equivalent. The comparison of calculations by the proposed method with the data of calculation in the Lira program using volumetric finite elements is presented. The comparison showed good agreement between the data. The average error was 6.9 percent and the coefficient of variation was $0.45 \%$. The proposed calculation method makes it possible to determine displacements in a normal crack without using software systems using volumetric finite elements. Being completely simple, the technique has sufficient accuracy for engineering calculations.

Key words: I-beam, normal crack, torsional stiffness, moment of inertia during torsion, equivalent stiffness.

\section{Azizov T.N.}

Doctor of Technical Science, Professor,

Pavlo Tychyna Uman State Pedagogical University, Uman, Cherkasy region

\section{Orlova O.M.}

Teacher,

Pavlo Tychyna Uman State Pedagogical University,

Uman, Cherkasy region 